\title{
Debates dos Estudos de Segurança Internacional e Segurança Humana: uma breve análise sobre a evolução dos Estudos de Segurança
}

Discussions of International Security Studies and Human Security: a brief analysis of the security studies

\author{
Mirela Nogueira de Alencar ${ }^{1}$
}

\begin{abstract}
RESUMO
Os estudos de Segurança Internacional são parte integrante dos estudos de Relações Internacionais, principalmente a partir do período de pós Guerra Fria. A temática de segurança pode ser vista em diferentes pontos de vista, e de diferentes áreas de estudos. Ao longo dos anos esses estudos avançaram para diferentes debates, como também a segurança humana, sendo na atualidade uma importante temática.
\end{abstract}

Palavras-chave: segurança; internacional, desenvolvimento.

\begin{abstract}
The International Security studies are an integral part of the studies of International Relations, mainly from the post-Cold War period. The security issue can be seen in different perspectives, and different fields of study. Over the years these studies advanced to different debates, as well as human security, and today an important issue.
\end{abstract}

Key-words: security; international; development.

\section{O QUE SÃO OS ESTUDOS DE SEGURANÇA INTERNACIONAL}

Segundo Buzan (2012) os estudos de Segurança Internacional surgiram após a segunda Guerra Mundial como uma forma de debate sobre as ameaças contra os Estados, bucando uma forma de como se dá a proteção destes. Os estudos de Segurança Internacional podem variar em relação ao tempo e o lugar. Não há uma composição objetiva do que realmente seja os ESI, o que leva consequentemente a diferentes perspectivas do que são estes estudos (BUZAN; HANSEN, 2012, p. 87).

\footnotetext{
${ }^{1}$ Mestranda em Ciência Política (UFPR), Curitiba, Brasil.

Conjuntura Global, Vol. 4, n. 2, maio/ago., 2015, p. 185-195.
} 
Os estudos de segurança se solidificaram principalmente no século XX após o período de Guerra Fria. Este período foi crucial para o desenvolvimento da visão dos estudos de segurança. Estudos acadêmicos passaram a incluir novas abordagens de segurança, do qual antes não eram incorporados. 0 que antes não era considerado um tema de segurança internacional, com o tempo os autores abordaram novos temas para que fossem inclusos nesses debates. Como por exemplo o tema de segurança ambiental e humana, que não eram considerados questões de segurança, mas na atualidade passaram a ser importantes debates da área (BUZAN; HANSEN, 2012, p. 87).

Após a segunda Guerra Mundial a visão realista se firmou como a principal teoria da disciplina de Relações Internacionais. Este período gerava análises principalmente sobre o cenário internacional anárquico e a busca constante dos Estados de aumentarem seu poder no sistema internacional. Porém, a teoria realista não conseguiu prever o fim da Guerra Fria, e isso gerou por consequência muitas críticas e questionamentos a esta visão. Estas críticas atingiram os estudos de segurança intenacional, o que incentivou a criação de novas teorias na área. Tais debates visavam definir novos significados para o conceito de segurança, que já eram utilizados nas relações internacionais. Buscavam ir além de conceitos realistas; já que o realismo associava segurança principalmente em torno de questões militares e estratégicas (TANNO, 2003, pg. 47). Um importante estudo desenvolvido na área de segurança é a Escola de Copenhague ${ }^{2}$, porém este trabalho não abordará os estudos dessa escola.

Os ESI podem envolver temas como soberania, autoridades, Estados, política, entre outros; entretanto, possuem principalmente ênfase em questões militares. Buzan e Hansen dividem no livro A evolução dos Estudos de Segurança Internacional (2012) os estudos de Segurança Internacional em quatro questões de debates, que são, "privilegiar o Estado como o objeto de referência; incluir tanto as ameças internas quanto as externas; expandir a segurança para além do setor militar e do uso da força; ver a segurança como inextricavelmente ligada a uma dinâmica de ameaças, perigos e urgências" (BUZAN;HANSEN, 2012, p. 100), com o intuito de demonstrar que outros temas e teorias podem ter relação com as ESI e que as diferentes dimensões compartilham uma mesma discursão.

\footnotetext{
${ }^{2}$ A Escola de Copenhague surgiu no Conflict and Peace Research Institute (COPRI) em 1985 na Dinamarca. Um importante escritor da Escola é Barry Buzan (1946). As principais contribuições da Escola de Copenhague para os estudos de segurança são o conceito de securitização, os novos temas de estudo de segurança e os setores abordados no campo da segurança (DUQUE, 2009, p. 470). 
A primeira questão supracitada em relação a segurança refere-se a algo que deve ser assegurado, seja o Estado, o meio ambiente, o indivíduo, entre outros. Neste caso a ideia de segurança pode ser tanto no âmbito nacional quanto no internacional. A segunda questão diz respeito a forma que os países devem se portar em relação as ameças aos seus territórios, sejam elas internas, como problemas econômicos, ou ameaças externas de outros países. A terceira questão leva em consideração outros debates que não são apenas questões militares e de uso da força, já que os ESI possuem uma forte tendência por essas áreas por ter surgido durante o período de Guerra Fria, e estava intrinsecamente ligado a questões militares. Sendo assim, posteriormente os estudos de segurança incluíra questões econômicas, sociais, ambientais, de gênero, outros. A quarta questão sobre os estudos de segurança leva em consideração que as ameaças e os perigos são fundamentais para os debates de segurança, porém podem ir além de apenas questões realistas com visão nos Estados. Questões liberais podem ser abordadas também, mas sem perder a dinâmica de ameaças e urgências (BUZAN;HASEN, 2012, p. 100).

A tendência dos estudos de segurança é de abordar os Estados e os indivíduos como objetos de referência. Mas os debates ocorrem principalmente em torno dos Estados, como já citado por Buzan e Hansen, afirmam que é um objeto privilegiado nesses estudos. A ideia de segurança estatal também está diretamente ligada a questão de segurança individual. Esta ideia vai de acordo com os pensamentos de Hobbes, do qual ele desenvolve a afirmação que para que os indivíduos estejam em segurança é necessário que uma instituição garanta. Desta maneira segurança é uma "condição tanto dos indivíduos quanto dos Estados" (ROTHSCHILD apud BUZAN;HANSEN, 2012, p. 101). Em relação ao Estado Buzan pontua duas diferentes linhas de análise quanto ao raciocínio de Hobbes em relação ao Estado e o indivíduo. Algumas linhas afirmam que alguns Estados são falidos e fracos para garantir segurança aos seus indivíduos, como por exemplo o caso do Haiti, que será o caso empírico analisado na última parte deste artigo. Outras linhas afirmam que os próprios Estados são uma ameaça para seus cidadãos, geralmente, ou principalmente, os não democráticos, dos quais não garantem segurança ambiental, ou a própria segurança humana, através de perseguições. Por exemplo países ditatoriais, como a União Soviética de Stálin (BUZAN; HANSEN, 2012, p. 101). 


\section{EVOLUÇÃO TEMÁTICA DOS DEBATES DE SEGURANÇA INTERNACIONAL}

Os ESI passaram por diferentes momentos e debates ao longo dos anos. 0 debate teórico de segurança internacional era tradicionalmente baseado em conceitos de poder e paz, principalmente nas décadas de 70 e 80 . A temática de poder são análises baseadas principalmente na teoria realista, dos quais importantes autores da área são Kenneth Waltz (1924), Hans Morgenthau (1904), Redley Bull (1932), entre outros. As contribuições realistas para o debate de segurança tratam essas questões de poder como a segurança dos Estados num sistema internacional anárquico. Kenneth Waltz (1979) no livro Theory of International Politics aborda como é possível mensurar poder. De acordo com Metternich (1773) e Bismarck (1815) poder era definido de acordo com as capacidades dos Estados, contudo estudantes contemporânes de políticas internacionais avançam essa definição a partir de novas condições (RUDZIT, 2005).

A temática de paz é abordada principalmente na teoria idealista, que visa analisar a garantia da segurança do sistema internacional a partir da segurança nacional. A teoria idealista ver que a segurança é resultante da paz. A paz gera segurança. Já a teoria realista aborda que o poder garante a segurança. 0 ator que possui poder, possui segurança. Após o período de Guerra Fria, no fim da década de 80 e início da década de 90, o enfoque dos debates passaram principalmente para o campo da economia. Com o fim da Guerra Fria passou-se a creditar que os assuntos econômicos dos Estados são mais importantes que assuntos militares (RUDZIT, 2005, p. 300).

011 de setembro de 2001 foi um marco histórico sobre o debate de segurança internacional. O uso da força voltou a ser um instrumento central das relações internacionais. Anteriormente a este período o terrorismo era considerado um debate periférico dos estudos de segurança, e não central. Os debates sobre terrorismo aumentaram, e até questões sobre religião foram inclusos em assuntos de segurança, especialmente pelo fato de que esse acontecimento ocorreu nos EUA. 011 de setembro demonstrou que os conflitos internacionais haviam estacionado temporariamente durante a década de 90, e que a retomada da tensão internacional é realidade internacional anárquica (BUZAN; HANSEN, 2012, p. 105). Os estudos de segurança retornam a visão realista, mas também com predominância dos atores não estatais. Autores neo-realistas como Posen (2001) e Walt (2001) debatem o 11 de setembro 
como uma política do Oriente Médio, e que Bin Laden é um ator racional (POSEN;WALT apud BUZAN;HANSEN, 2012, p. 110).

Os debates de segurança no início do século XXI foram influenciados pelo marco terrorista do 11 de setembro. Questões como segurança regional, tecnologia, segurança no Oriente Médio, entre outros. Em relação a segurança regional os debates sederam principalmente sobre a região Sul e Sudeste da Ásia, Ásia Central e África, como por exemplo, discussões sobre a proliferação nuclear. A segurança regional recebeu atenção principalmente nas guerras internas ocorridas no terceiro mundo. A preocupação dos estudos estavam direcionados a manutenção da paz e o desenvolvimento nos Estados considerados fracos e falidos. Sendo assim, os estudos focavam em temas como interveções humanitárias e manutenção da paz, em conflitos considerados uma ameaça aos Direitos Humanos. A crise humanitária passou a um ser um tema importante de agenda de segurança (ROBERTS apud BUZAN e HANSEN, 2012, p. 105).

Buzan e Hansen citam que os estudos de segurança possuem certas limitações em algumas temáticas, o que eles chamam de Ocidente-centrismo. Esses estudos são Ocidentais, ou anglo-americano, e apenas abordam o Terceito Mundo, por exemplo, quando possui alguma relação com as grandes potências. Sendo assim esses estudos ficam limitados para uma grande parte não Ocidental. (BUZAN;HANSEN, 2012, p. 110).

Na parte três deste artigo será abordado brevemente como se dá o debate da teoria póscolonial nos estudos de segurança Internacional, e como os estudos de segurança humana fazem parte, e se desenvolveram, nos estudos de segurança internacional.

\section{DEBATE DE SEGURANÇA HUMANA E PÓS-COLONIAL NOS ESTUDOS DE SEGURANÇA INTERNACIONAL}

Os estudos de segurança pós-coloniais recebem críticas pela ocidentalização dos conceitos, dos quais tais conceitos podem não ser aplicáveis empiricamente em países de terceiro mundo, por exemplo. Segundo antropólogos que possuem uma visão póscolonial, os estudos de campo etnográficos podem indicar diferentes modos de construção de segurança de acordo com as culturas locais. E esta construção se difere dos analisados nos estudos de segurança ocidentais, que analisam a segurança como 
modo de garantia de seus cidadãos e dos Estados. Os diferentes meios que as sociedades de diversas culturas se estruturam demonstram que há uma variação política, econômica e social de organização. 0 modo que essas sociedades se estruturam necessita que a epistemologia e a metodologia de análises de segurança sejam vistos de maneira especial e diferenciado, não apenas com a visão realista tradicional (BUZAN;HASEN, 2009, p. 120).

Os estudos de segurança internacional pós-coloniais abordam principalmente os Estados não ocidentais, as estruturas econômicas, e também assuntos de desenvolvimento. Em relação aos estudos de desenvolvimento, esses se formaram dentro do conceito de segurança humana, lançado em 1994 pelo Programa das Nações Unidas para o Desenvolvimento (PNUD), através do Relatório de Desenvolvimento Humano. A PNUD define segurança humana como parte fundamental do desenvolvimento humano. 0 ponto de vista do desenvolvimento humano, segundo a PNUD, é que as pessoas possam ter capacidade e oportunidade de ser aquilo que elas desejam, indo além do viés econômico, do qual o crescimento econômico não é o ponto principal do desenvolvimento, mas é um fim. Para que haja desenvolvimento é preciso que outras áreas, além das econômicas, avancem, como a social, cultural e política (PNUD, 2014).

Os impactos nestas áreas podem levar à inseguranças das pessoas, impedindo o desenvolvimento e aumentando a vulnerabilidade. Em países em que os índices de desenvolvimento são baixos há realidade de longos períodos de conflitos e violência. Segundo a PNUD "em algumas regiões da África Ocidental e Central, situações de anarquia e conflito armado continuam a fazer perigar os avanços no domínio do desenvolvimento humano, com reflexos a longo prazo no progresso nacional" (Relatório de Desenvolvimento Humano, 2014). Sendo assim, o desenvolvimento humano é parte fundamental do conceito de segurança humana segundo a perspectiva pós-colonial.

Os estudos de segurança humana começaram a surgir recentemente em estudos acadêmicos como uma área dos estudos de segurança internacional. Essa área busca encorajar os estudiosos a analisarem a área de segurança além de questões militares, ou de segurança territorial. Os estudos de segurança humana possuem sete elementos principais de análise, que são a segurança econômica, alimentar, saúde, ambiental, pessoal, comunidade e política (PARIS, 2001, p. 97). 
Nos estudos de Relações Internacionais a segurança humana é considerada como uma nova teoria, ou conceito, e pode ser classificada até mesmo como um paradigma. A Segurança humana ganhou destaque desde a II Guerra Mundial, com a ideia de que os direitos dos seres humanos são tão importantes quanto os direitos dos Estados. E seguiu com destaque durante o período da Guerra Fria, porque a maioria das casualidades da guerra foram de seres humanos. Muitas crianças passaram a ser recrutadas para serem soldados, e o estrupo se tornou uma prática comum. Sendo assim, a segurança humana passou a fazer parte da agenda internacional com a tentativa de responder a uma realidade global de Estados falidos (FIERKE, 2015, p. 156 e 157). Segundo McRae (2001) quando Estados são falidos, quem mais sofre são os seres humanos, já que o sistema internacional do século XX foi designado para proteger Estados, a soberania dos Estados e conflitos entre os Estados. Sendo assim, o sistema internacional está lutando para proteger os civis que estão dentro dos Estados (FIERKE, 2015, p. 157).

O conceito de Segurança Humana surgiu a partir de vários conceitos. 0 primeiro conceito foi introduzido pela Comissão de Brundtland, em 1987, e foi o desenvolvimento sustentável. Esta comissão afirma que a proteção ambiental é necessária para a sobrevivência da humanidade a longo prazo, a partir de qualquer estratégia de desenvolvimento (World Commission on the Environment and Development 1987). 0 segundo conceito foi introduzido pelo Programa de Desenvolvimento das Nações Unidas em 1990, que foi o desenvolvimento humano. 0 relatório afirma que as pessoas devem ser o centro de todo desenvolvimento (FIERKE, 2015, p. 158).

A segurança humana está na agenda política de muitos Estados, organizações governamentais, não-governamentais internacionais e das Nações Unidas. Conforme supracitado, o conceito de segurança humana vai além da militarização, ou seja, conceito de segurança realista, mas também aspectos como segurança contra a fome, a pobreza, repressão, outros. A segurança humana está ligada ao bem-estar, justiça e dignidade humana; e interligado com os Direitos Humanos e o desenvolvimento. É uma forma da garantia da proteção dos indivíduos. Assim como na visão realista um país deve proteger seu território de ameaças bélicas, a visão de segurança humana está ligada a proteção da população. A segurança humana pode ser entendida como uma proposta moral ao realismo, pois avança da proteção unicamente do território para o nível da proteção dos indivíduos (TADJBAKHSK; CHENOY, 1995). Para o PNUD a essência de inseguraça humana é a vulnerabilidade, e a pergunta principal é: como proteger as pessoas? Sendo Conjuntura Global, Vol. 4, n. 2, maio/ago., 2015, p. 185-195. 
assim, o PNUD acredita que não haverá paz no mundo enquanto as pessoas não estivem em segurança no seu dia-a-dia (FISAS apud BAZZANO, 2011). A figura abaixo mostra a ideia de que o indivíduo é a base da segurança humana.

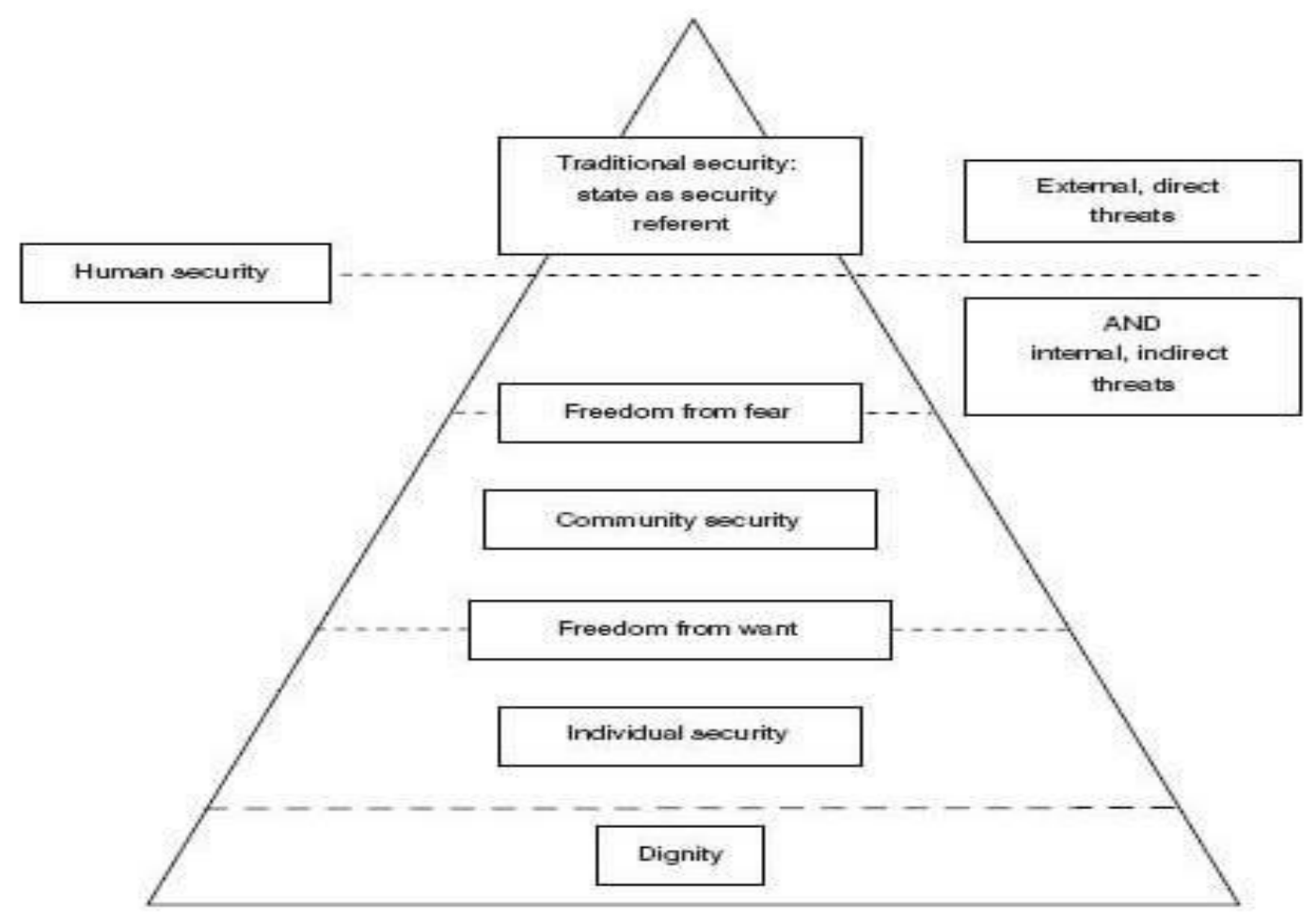

Fonte: Shahrbanou Tadjbakhsh e Anuradha Chenoy, $2009^{3}$

A insegurança humana pode ser vista como uma forma de interdependência, tendo em vista que os sete principais elementos da segurança humana são interligados, e tendo alguma ameaça a pelo menos um desses elementos, a insegurança será propagada para os outros elementos. Os estudiosos da área acreditam que as ameaças são transnacionais, já que podem acontecer tanto a partir de outros Estados, de atores não-estatais ou de relações de poder. A transnacionalidade da ameaça quer dizer que não há fronteiras definidas para que os indivíduos sejam ameaçados. Sendo assim, a interdependência acontece na prevenção dessas ameaças, a partir da ideia de que Estados devem estabelecer uma cooperação entre si, para que as ameaças não

\footnotetext{
${ }^{3}$ A fonte da figura não possui página, pois foi extraída de uma versão e-book. Conjuntura Global, Vol. 4, n. 2, maio/ago., 2015, p. 185-195.
} 
aconteçam, refletindo assim num mundo interdependente (ARAVENA apud BAZZANO, 2011).

Apesar da importância e significância que os estudos de segurança humana possuem dentro das Relações Internacionais, este debate possui críticas quanto ao seu método de conceito e de abordagem. 0 debate de segurança humana recebe críticas quanto a mensuração do conceito, e sobre se realmente a questão da segurança humana é de fato uma questão da área de segurança internacional, do qual deveria ser abordado como uma literatura de pobreza, saúde e desenvolvimento, ao invés da área de segurança. Esta crítica se baseia no fato de que o indivíduo é o centro da abordagem, tanto espitemologicamente como empiricamente, e que as abordagens políticas e internacionais acabam ficando ausentes do debate (KING; MURRAY apud BUZAN; HANSEN, 2009, p. 115). Apesar de receber críticas por ter o foco no indivíduo, na maioria dos casos, esses esforços de diferentes abordagens são solicitados por contribuições de críticos e estudiosos pós-colonialistas, com a tentativa de ampliar os estudos de segurança, indo para além da análise dos Estados (PARIS, 2001, p. 102).

Outras críticas são, por exemplo, que a segurança humana é supostamente como uma forma do realismo clássico, ou seja, não muda a ideia de preocupação com o território nacional e dos interesses nacionais. Já que, apesar da abordagem humanitária, a busca da proteção continua sendo territorial. A segurança humana é criticada também por ser tão ampla como conceito, que acaba sendo vazia politicamente e academicamente. Para Paris (2001) "se a Segurança Humana significa qualquer coisa, então ela não significa, efetivamente, nada" (PARIS apud BUZAN; HANSEN, 2009, p. 308). Outros críticos também apontam a ideia de que esta segurança deveria ser inclusa numa agenda de direitos humanos. E também que a natureza da definição é institucionalizada, já que o seu documento está dentro do PNUD (BUZAN; HANSEN, 2009, p. 308).

\section{CONSIDERAÇÕES FINAIS}

Observa-se que os estudos de Segurança Internacional passaram por diferentes fases e abordam diferentes pontos de vista de análise. Tendo em consideração a evolução dos estudos de segurança, é possível observar que tais estudos passaram por diferentes períodos, sendo de acordo com a agenda internacional. No geral, pode ser 
levado em consideração, que os estudos de segurança passaram de apenas uma abordagem realista, para análises mais amplas, como a segurança humana. Outro avanço sobre os estudos de segurança foi na territorialidade da abordagem, ou seja, os conflitos regionais também passaram a ter importância nos estudos de análise de segurança internacional. Os conflitos regionais passaram a ser uma preocupação internacional, não apenas local. Porém, apesar do avanço no debate de segurança, o tema possui críticas em relação, por exemplo, a limitação das análises; já que a maioria dos estudos de segurança se limita principalmente ao Ocidente limitando, pode-se dizer, a abordagem de países e conflitos de terceiro mundo.

A segurança humana apesar de está diretamente relacionada aos estudos de segurança internacional, possui destaque como importante debate nos estudos da área. 0 desafio dos estudos de segurança humana dentro dos estudos de segurança internacional é abordar o indivíduo como principal objeto de análise, indo além do foco nos Estados. Os debates de desenvolvimento e de segurança eram considerados de forma separada, e com a evolução dos estudos o desenvolvimento passa a ser parte fundamental da segurança. A segurança não é mais apenas um fim, mas passa a ser um meio. Sendo assim, o desenvolvimento humano é parte fundamental da segurança internacional.

\section{REFERÊNCIAS}

DUQUE, Guedes Marina. 0 papel de síntese da Escola de Copenhague nos estudos de segurança internacional. Revista Contexto Internacional, Vol. 31 no 3: Rio de Janeiro 2009, p. 459-501

FIERKE, K. M. Critical Approaches to International Security. Cambridge: Polity, ed 2,2015, p. 1-234.

HASEN, Lene; BUZAN, Barry. The evolution of international security studies. Cambridge: Cambridge University Press, 2009, p. 1- 398.

PARIS, Roland. Human Security: Paradigm shift or hot air? Massachusetts: Vol. 26, No. 2 (Fall 2001), p. 87-102

Relatório do Desenvolvimento Humano 2014. Programa das Nações Unidas para o Desenvolvimento, 2014. 
RUDZIT, Gunther. 0 debate teórico em segurança internacional. Mudanças frente ao terrorismo? Porto Alegre: Civitas - Revista de Ciências Sociais, vol. 5, núm. 2, julhodezembro, 2005, Pontifícia Universidade Católica do Rio Grande do Sul. P. 297-323

TADJBAKHSK, Shahrbanou; CHENOY, M. Anuradha. Human security - concepts and implications. London: Routledge, 2009.

TANNO, Grace. A contribuição da Escola de Copenhague aos estudos de segurança internacional. Revista Contexto Internacional, Vol. 25 nำ 1: Rio de Janeiro, 2003, p. 47-80. 